\title{
Modeling a Logistics Pooling Strategy for Agri-Food SMEs
}

\author{
Abdelhamid Moutaoukil $^{1}$, Ridha Derrouiche ${ }^{2}$, and Gilles Neubert ${ }^{2}$ \\ ${ }^{1}$ Institut Fayol- UMR-5600, EMSE, 158 cours fauriel, Saint-Etienne, \\ 42000 Saint-Etienne, France \\ ${ }^{2}$ UMR-5600, ESC Saint-Etienne 51-53 cours Fauriel BP29 - 42000 \\ Saint-Etienne, France
}

\begin{abstract}
This paper presents an innovative approach to improve sustainability of logistics pooling strategy by reducing $\mathrm{CO} 2$ emissions and social incidents. Our approach aims to increase the collaborative network efficiency in the context of agri-food SMEs. The combination of discrete event simulation and analytical optimization approaches enables to analyze different pooling scenarios and to optimize pooled distribution network. The developed model takes into account the specificities of agri-food SMEs flows. The thereby improved utilization of logistics resources impacts economic and ecological and societal performance indicators.
\end{abstract}

Keywords: Logistics Pooling, Sustainable development, Agri-food SMEs, Discrete event modeling.

\section{Introduction}

To be competitive, manufacturers must optimize their supply chain. This optimization, long based on an economic approach; happen today through the integration of environmental and social concerns, in line with the objectives of sustainable development [1]. In addition, a constant pressure of European regulations pushes industry to integrate sustainability concerns in their supply chains. The regulatory developments translates into economic terms, with the Modernization Law Economy-LME whose objective is lower selling price to consumers [2], or notably with Grenelle law (- $20 \%$ emission of greenhouse gas emissions by 2020), or with the new Ecotax law.

In this context, new requirements have been added to the requirements of economic efficiency. Logistics systems must now meet the requirements of sustainable development, namely:

- At the Economic Level: reducing logistics costs.

- At the Ecological Level: reduce both $\mathrm{CO} 2$ emissions and energy consumption, with an incentive to make more recycling and waste treatment [3] and [4].

- At the Societal Level, take into consideration the expectations of different stakeholders in the process of making business decisions [5] and [6]. 
These requirements are more difficult to reach for SMEs, because their logistics performance does not allow them to engage in a sustainable approach [7] and [8]. In addition, Just in Time-JIT policy has been implemented in most sectors: to deliver faster, more frequently and in small quantities. These changes in flow management explode SMEs logistics costs, which endangers the entire implementation of a sustainable development approach. In this context of accelerating flow and inventory reduction, logistics sharing between SMEs is more than ever at the heart of priorities. These are strategic decisions for these companies: what is the structure of a pooled logistics network to ensure a better economic, environmental and social performance?

\section{Research Context and Approach}

In the continuation of literature review presented in [9], logistics pooling was treated in three ways: $i$ ) The pooling of transport and platforms from a single source in order to serve a set of customers [10], [11] and [3]. ii) The pooling of transport and platforms of a set of suppliers to serve one or more clients [12], [13], [14] and [15]. iii) The pooling of transport with vehicle routing and exchange delivery orders between carriers to reduce empty returns and increase the use of means of transport [15] and [16].

In this literature, taking into account the objectives of sustainable development is recent. The research work of [13] focused on the economic dimension, while the work of [17] and [14] introduced the environmental dimension by calculating the $\mathrm{CO} 2$ emissions of their scenarios. Sustainable development is mostly treated as an environmental perspective while the societal dimension is generally not considered.

Finally, previous studies consider important flow treaties in number of pallets, mostly in retail distribution. These studies generally consider a stationary demand and call upon distribution systems of batch of products which occur according to long delays in the distribution network, particularly through storage platforms. The importance of massified flow in these contexts provides the ability to transit to other means of transportation that are more economical and ecological (e.g. rail), as studied in [17] and [12].

The specificity that we have identified in the context of agri-food sector, resides on a modality of logistic flow of small quantities, expressed in number of parcels (a few pounds) to be distributed in $\mathrm{J}+1, \mathrm{~J}+2$ or in $\mathrm{J}+3$ to different destinations through different operations: loading, consolidation, unbundling and distribution. This service falls within the "express mail" and based on small transport systems. Economic criteria sometimes push these agri-food SMEs to delay deliveries, even losing orders to avoid logistical costs associated with too small shipments.

Finally, research on logistics pooling as in [13], [14] and [17] are based on analytical methods and call upon strong constraints to simplify their models: e.g. fixing the carrying capacity, or the failure to take into account the factor "loaded weight" for the calculation of $\mathrm{CO} 2$ emissions in vehicle routing.

For our research, it is essential to consider the constraints of transportation as a variable in the performance evaluation of pooled networks, which bring us to test various hypotheses, more appropriate to express small package. For this, we chose use methods based on simulation. Among its advantages, simulation offers the possibility 
to take into account realistic assumptions (compared to analytical models). However, the results are only valid for studied scenarios, and to be generalizable, it must conduct a sensitivity analysis of the model relative to different parameters. Our goal is to compare the performance of a traditional logistics network with different models of pooled logistics networks. Given the complexity of logistics systems and the difficulty to take into account different constraints in analytical model, the simulation appeared to us as the most appropriate tool for this research.

\section{$3 \quad$ Modeling a Logistics Pooling Strategy}

Logistics pooling is a partnership agreement that involves voluntary pooling of physical and information and skills in order to achieve economic and environmental and social gains, or to counter in the short term a constraint or to access a service unavailable individually [9]. The framework of this partnership can assume various organizational forms depending on the nature of the partners and resources and products [18].

Modeling Approach. To model a logistics pooling strategy, we first define different pooled schemas (sharing scenarios). To model these different scenarios, we construct a model which consists of a simulation model coupled with an optimization model. The simulation model is used to simulate different scenarios and the optimization model is used to optimize vehicles routing in certain scenarios. To choose the most relevant scenarios, we develop a system of performance indicators to evaluate and compare different scenarios.

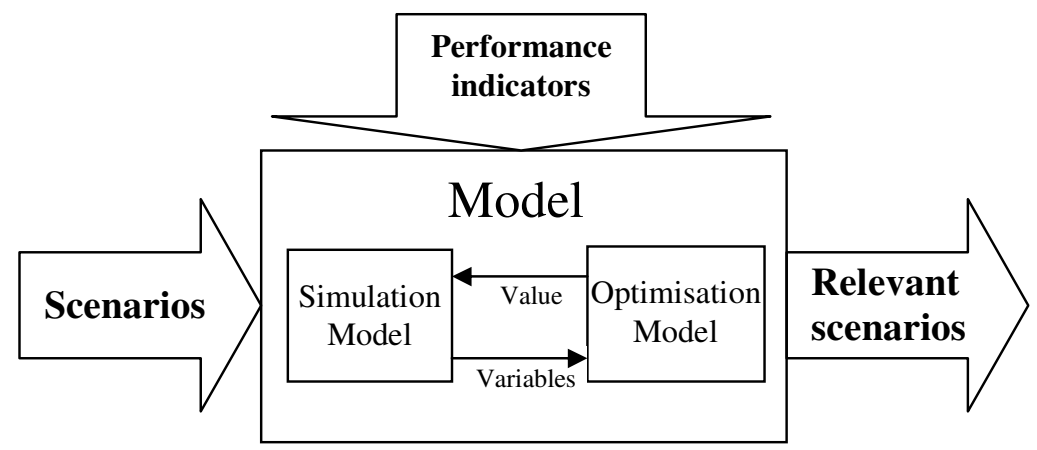

Fig. 1. Modeling approach

Scenarios Development. The various possibilities of pooling are based on two main principles: transport pooling and platforms pooling. Based on these two types of pooling, we identified different scenarios (Table 1).

We consider two configurations: C1 (Many to one) where a set of manufacturers distribute their products to a single common client and C2 configuration (Many to Many), in which several clients deliver a set of manufacturers that are not necessarily

common using or not a cross docking platform. Scenarios with a storage platform are normally possible in a logistics pooling strategy. In our particular case, given the 
above requirements on the agri-food SMEs, including short delivery time of small parcels, we will not take into account these scenarios.

Table 1. Various scenarios of logistics pooling

\begin{tabular}{|c|c|c|c|c|c|c|c|}
\hline \multirow[t]{2}{*}{ Configuration } & \multirow{2}{*}{.气̊: } & \multicolumn{2}{|c|}{ Transport upstream } & \multicolumn{2}{|c|}{$\begin{array}{l}\text { cross dock } \\
\text { plateform }\end{array}$} & \multicolumn{2}{|c|}{$\begin{array}{l}\text { Transport down- } \\
\text { stream }\end{array}$} \\
\hline & & Direct & Multi-pick & Yes & No & Direct & $\begin{array}{l}\text { Multi- } \\
\text { drop }\end{array}$ \\
\hline \multirow{3}{*}{$\begin{array}{l}\text { C1 } \\
\text { Many to One }\end{array}$} & S0 & $\downarrow$ & & & $\checkmark$ & 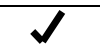 & \\
\hline & $\mathrm{S} 1$ & & $\checkmark$ & & $\checkmark$ & $\checkmark$ & \\
\hline & S2 & $\checkmark$ & & $\sqrt{ }$ & & $\sqrt{ }$ & \\
\hline \multirow{6}{*}{$\begin{array}{l}\text { C2 } \\
\text { Many to } \\
\text { Many }\end{array}$} & S0 & $\checkmark$ & & & $\checkmark$ & $\checkmark$ & \\
\hline & S1 & & $\checkmark$ & & $\checkmark$ & & $\checkmark$ \\
\hline & $\mathrm{S} 2$ & $\checkmark$ & & $\sqrt{ }$ & & & $\sqrt{ }$ \\
\hline & S3 & $\downarrow$ & & $\checkmark$ & & $\checkmark$ & \\
\hline & S4 & & $\checkmark$ & $\sqrt{ }$ & & & $\checkmark$ \\
\hline & S5 & & $\sqrt{ }$ & $\sqrt{ }$ & & $\checkmark$ & \\
\hline
\end{tabular}

S0 scenario for both configurations refers to the initial situation, without pooling. For C2 configuration, transportation between partners can be directly to the cross docking platform or in multipick mode (vehicles routing for collecting products). Delivery transport to different customers can be also either directly from the cross docking platform or in multidrop mode (vehicles routing for the distribution of products).

Proposed Model: Assumptions and Parameters. The proposed model in C2 configuration is a logistics network with I manufacturers and J clients. All companies are at the same level of decision and there is information sharing. Since we are interested only in patterns of distribution, we ignore the production processes of manufacturers, and it is assumed that they have an infinite stock of finished products.

For each customer $i$, the demand for a product of reference $\mathrm{j}$ follows a normal distribution with mean $X_{j}^{i}$ and standard deviation $Y_{j}^{i}$ with an arrival rate $F$, over a period $\mathrm{T}_{\mathrm{j}}$ of the year. To take into account the seasonality of products in the agri-food sector, we consider that a further period $\mathrm{T}_{\mathrm{j}}^{\prime}$ of the year, demand for the same product $\mathrm{i}$ to the same customer $\mathrm{j}$ follows a normal distribution with mean $\mathrm{X}_{\mathrm{j}}^{\mathrm{i}}$ and standard deviation $\mathrm{Y}_{\mathrm{j}}^{\prime \mathrm{i}}$ with arrival frequency $\mathrm{F}^{\prime}$. Demand is directly transformed in order of delivery of finished products. Daily delivery orders to the same destination are consolidated.

To give an overview of the modeling we have done, this paper is focused on the example scenario C2S2. This strategy aims to establish cross dock platforms that collect parcels from several manufacturers, consolidates these expeditions, and directs them to the appropriate client in grouped form. 
The objective of this scenario is to assign platforms consolidation to suppliers and to customers to improve network performance. We select an appropriate number of platforms from potential hubs, and assign suppliers to different platforms. Platforms receive products from manufacturers and consolidate all products that have the same destination before sending products to the customer in question.

Each company has a physical system composed of an infinite stock module of finished product, a "Preparing order" process and a transport module for the products delivery to the platform. Production processes are ignored. Transport module simulates the transport and delivery times. This module is composed of a transport resource that includes a human resource (driver) and a truck from a heterogeneous fleet of trucks. The capacity of the truck is chosen according to quantity to be carried. A $\mathrm{CO} 2$ emissions calculator is connected to transport module.

At the platform, is made cross-docking operations of different manufacturers' references that are consolidate according to different destinations. In this perspective, we can consider that the cross-dock operations are summarized in their time, with generation of costs.

We make the following general assumptions:

- Each supplier produces a single product [if a supplier produces different products, we can create an additional fictitious provider for each additional type of product]

- All products are compatible and stackable.

- Deliveries are made into A to $\mathrm{C}$ (Command sent the day $\mathbf{J}$ and received the days $\mathrm{J}+2$ )

- The capacity of transport is limited by weight and volume.

- Transportation in the logistics network is operated by a carrier.

- Each platform can serve more than one customer and each customer can be served from multiple platforms. There are no links between platforms.

Vehicle Routing Optimization. Among the scenarios that we consider, we find several scenarios that are based on vehicle routing. The optimization of vehicle routing problem is in tactical-operational level of decision-making. While the issue of our research concerns the design of logistics distribution network that reports to the strategic level of decision-making. However, optimization of vehicle routing is important, because it contributes to the evaluation of different scenarios.

For this purpose, we build an optimization system of vehicle routing which is based on three-step, as shown in the following figure. The proposed optimization system begins by determining the optimal tour passes through all manufacturers and minimizes the traveled distance. In a second step, the constraint of back time to the platform is introduced. This time constraint is the maximum duration not to exceed by a tour vehicle. With this constraint, we determine the exact number of tours to do. Knowing the manufacturers included in each tour and the amount to be charged at each, we can specify the capacity truck to send on each tour.

The optimization of vehicle routing model is coupled to the simulation model of different scenarios. 


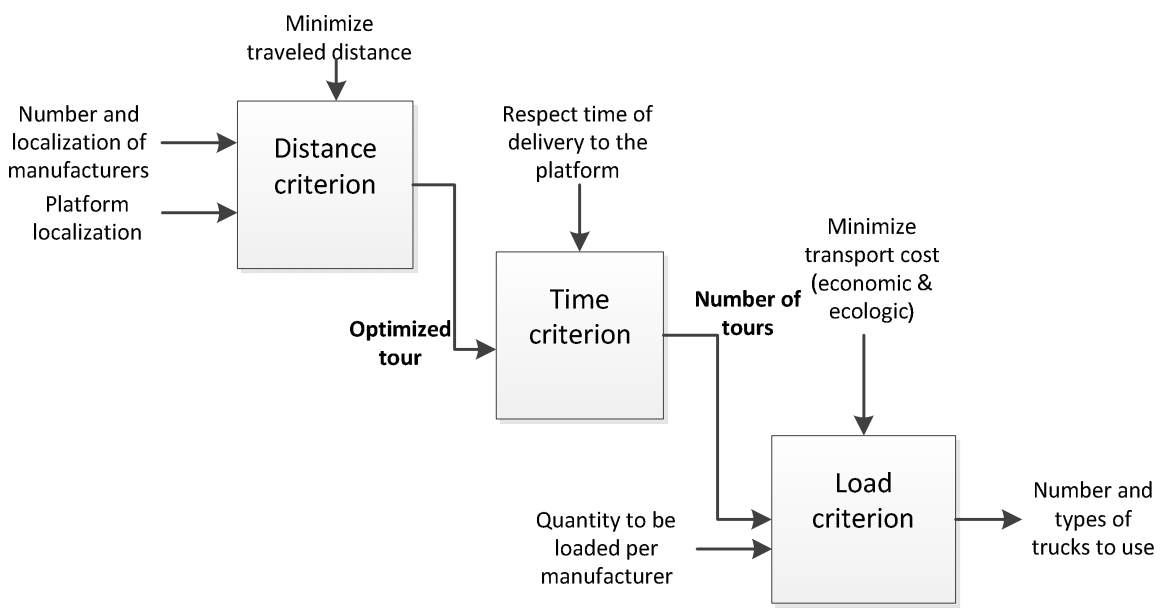

Fig. 2. Optimization model of vehicles routing

\section{$4 \quad$ Parameters and Performance Indicators}

We have summarized in Table 2, all data and parameters necessary for the simulation of $\mathrm{C} 2 \mathrm{~S} 2$ scenario. These parameters are used to evaluate the various performance indicators for this scenario, which then allow us to make a comparison with the other scenarios.

Economic Indicator. Throughout logistics network, three cost factors are considered: transportation cost, cross-docking cost and handling costs. Handling cost includes cost of loading and unloading. The total logistics costs of each scenario are calculated using the following formula:

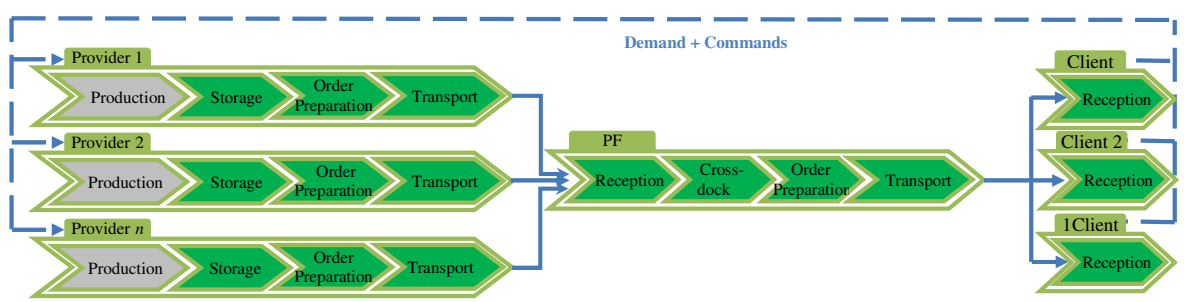

Fig. 3. Simulation Model of $\mathrm{C} 2 \mathrm{~S} 2$ scenario 
Table 2. Parameters and constraints and performance indicators of C2S2 scenario simulation

\begin{tabular}{|c|c|c|c|c|c|c|c|c|c|}
\hline \multirow{2}{*}{$\begin{array}{l}\text { Physical } \\
\text { Processes }\end{array}$} & \multicolumn{3}{|c|}{ Provider (s) } & \multicolumn{4}{|c|}{ Platform of cross-dock (PF) } & \multicolumn{2}{|l|}{ Client(s) } \\
\hline & Stockage & $\begin{array}{c}\text { Order } \\
\text { Preparation }\end{array}$ & Transport & Reception & \begin{tabular}{|l|}
$\begin{array}{l}\text { Cross- } \\
\text { dock }\end{array}$ \\
\end{tabular} & $\begin{array}{l}\text { Preparation } \\
\text { commands }\end{array}$ & Transport & Reception & Demand \\
\hline $\begin{array}{l}\text { Data and } \\
\text { Parameters }\end{array}$ & $\begin{array}{l}\text {-Quantity } \\
\text { of } \\
\text { storage } \\
\text { (Infinite) }\end{array}$ & $\begin{array}{l}\text {-load } \\
\text { cost/parcel } \\
\text {-load time/ } \\
\text { parcel } \\
\text {-delivery } \\
\text { frequency/ } \\
\text { client } \\
\text { provider }\end{array}$ & $\begin{array}{l}\text {-Distance between clients } \\
\text {-Distance betwecn PF and } \\
\text { providers (manufacturers) } \\
\text {-Transport cost/ parcel } \\
\text { / km/t } \\
\text {-Available transport } \\
\text { Capacity. } \\
\text {-Transport time (Providers/ } \\
\text { platform) } \\
\text { - CO2 Emission } \mathrm{kg} / \mathrm{km} \\
\text { - Maximum driving time }\end{array}$ & $\begin{array}{l}\text {-Unload } \\
\text { cost/parcel } \\
\text {-Unload } \\
\text { time/parcel } \\
\text {-time- } \\
\text { windows }\end{array}$ & \begin{tabular}{|l|}
-Cross- \\
dock cost \\
/parcel \\
- cost of \\
passage \\
through \\
platform
\end{tabular} & $\begin{array}{l}\text {-load } \\
\text { cost/parcel } \\
\text {-load time/ } \\
\text { parcel } \\
\text {-dclivery } \\
\text { frequency }\end{array}$ & $\begin{array}{l}\text {-Distance between } \\
\mathrm{PF} \text { and clicnts } \\
\text {-Transport cost/ } \\
\text { parcel/km/t } \\
\text {-Available transport } \\
\text { Capacity } \\
\text { - Transport time } \\
\text { (platform/ client) } \\
-\quad \mathrm{CO} 2 \quad \text { Emission } \\
\mathrm{kg} / \mathrm{km} \\
\text { - Driving time }\end{array}$ & $\begin{array}{l}\text {-Time- } \\
\text { windows }\end{array}$ & $\begin{array}{l}\text {-Daily } \\
\text { Demand / } \\
\text { client } \\
\text { /provider } \\
\text {-Standard } \\
\text { deviation of } \\
\text { daily } \\
\text { demand/ } \\
\text { client } \\
\text { /provider }\end{array}$ \\
\hline Constraints & & & $\begin{array}{l}\text { Limited carrying capacity } \\
\text { (weight, volume) }\end{array}$ & & & & $\begin{array}{l}\text { Limited carrying } \\
\text { capacity }\end{array}$ & $\begin{array}{l}\text { Time } \\
\text { window }\end{array}$ & \\
\hline $\begin{array}{l}\text { Economic } \\
\text { Indicator }\end{array}$ & & Load Cost & Transport cost & $\begin{array}{l}\text { Unload } \\
\text { Cost }\end{array}$ & $\begin{array}{l}\text { Cross- } \\
\text { dock cost }\end{array}$ & Load Cost & Transport cost & $\begin{array}{l}\text { Unload } \\
\text { Cost }\end{array}$ & $\begin{array}{l}\text { Total } \\
\text { unload time }\end{array}$ \\
\hline $\begin{array}{l}\text { Enviro- } \\
\text { Indicator }\end{array}$ & & & C02 Emission & & & & C02 Emission & & \\
\hline $\begin{array}{l}\text { Societal } \\
\text { Indicator }\end{array}$ & & & $\begin{array}{l}\text { - Accident Risk } \\
\text {-Number of used trucks }\end{array}$ & & & & $\begin{array}{l}\text { - Accident Risk } \\
\text {-Number of trucks }\end{array}$ & & \\
\hline
\end{tabular}

$$
\begin{aligned}
\text { Total Cost }\left(\boldsymbol{S}_{i}\right)= & \sum \text { transport Cost }+\sum \text { loading Cost }+\sum \text { unloading Cost } \\
& +(\text { Mode })\left[\sum \text { unloading Cost }+\sum \text { Cross }-\right. \text { docking Cost } \\
& \left.+\sum \text { loading Cost }\right]
\end{aligned}
$$

With:

Mode $=0:$ No passage through Platform

Mode $=1:$ passage through Platform

We have proposed a method of calculating the total cost of transportation (provided by the carrier) summarized in this formula:

Transport cost $=$ Variable cost + hourly cost + Fixed cost

Variable cost $=$ Traveled distance $*$ cost per kilometer

Hourly cost $=($ Load time + Transport time + Unload time $) *$ cost per hour

Fixed cost $=[(\text { Load time }+ \text { Transport time }+ \text { Unload time }) / \text { Working time }]^{*}$ Fixed cost Transport time $=$ Traveled distance $/$ average speed

The transportation cost for each manufacturer is a function of the quantity transported, the distance, travel time and the type of truck used.

Environmental Indicator. We summarize the environmental indicator in $\mathrm{CO} 2$ emissions. To model CO2 emissions, we rely on references [17], [19] and [20].

To calculate $\mathrm{CO} 2$ emissions, we must model the distance between manufacturers, between clients, and the distance between platforms and manufacturers and customers. We must also consider the weight carried. In fact, $\mathrm{CO} 2$ emissions depend on the weight carried, on the capacity of the truck used, the distance traveled and the average speed of the travel. The average speed of course depends on the type of path in regional or national routes. 
We have adapted the formula given by [15] and [18], to calculate the CO2 emissions based on truck type $\mathrm{k}$, by setting the value of the average speed for each location:

$$
\boldsymbol{\varepsilon}(d, x, k)=d *\left[\left(\boldsymbol{E}_{\text {full }}^{k}-\boldsymbol{E}_{\text {empty }}^{k}\right) * \frac{X^{P}}{\boldsymbol{C}_{\boldsymbol{k}}^{P}}+\boldsymbol{E}_{\text {empty }}^{k}\right]
$$

Avec :

$\mathrm{d}:$ travled distance

$\mathrm{E}_{\text {full }}^{\mathrm{k}}$ : Emission of truck type $\mathrm{k}$ in full load

$\mathrm{E}_{\mathrm{empty}}^{\mathrm{k}}$ : Emission of empty truck type $\mathrm{k}$.

$\mathrm{X}^{\mathrm{P}}$ : Total weight of transported parcel

$\mathrm{C}_{\mathrm{k}}^{\mathrm{P}}$ : Weight capacity of $\mathrm{k}$ type truck.

The calculation of emission $\mathrm{E}_{\mathrm{full}}^{\mathrm{k}}$ and $\mathrm{E}_{\mathrm{empty}}^{\mathrm{k}}$ according different transport capacity are based on the data provided in [19] [20].

Societal Indicator. In France, more than $80 \%$ of freight transport is done by road transport [21], this leads to strongly solicit transport system and infrastructure. Trade in goods actually creates congestion on some roads, insecurity and various nuisances to the public.

Therefore, other criteria must be taken into account when evaluating logistics pooling projects, which are societal incidents on the various parties involved in such projects. Two parties are mostly affected: carriers and residents. Carriers are the main actors of transport pooling, and their needs and expectations should be taken into account. Any reduction in the number of kilometers traveled, helps reduce the risk of accidents. Decreasing congestion, reducing the number of trucks involved in logistics pooling projects, also plays a role in reducing accident risk. For our purposes, we chose to use the shipping rate and traveling distance for the accident risk assessment.

The second stakeholder is the rest of the population, who are not directly involved in the transport of goods, but who share the same transport network. Network congestion by trucks, which increases especially near to logistics areas (platforms), the noise and blocking streets causes of trucks, and other situations are considered negative by residents. Thus, a logistics pooling system that reduce congestion, or reduce the perception of large vehicles in transportation networks can be considered as a good solution. Note that all of these indicators are difficult to quantify empirically, because they are linked to more sociological aspects. For this reason, we consider the indicator of the number of trucks used, which can tell us about other less quantifiable indicators.

\section{Conclusion}

The particular case of agri-food SMEs logistics pooling is an original issue not addressed in the literature. In this context, our work proposes a new model that integrates characteristics of agri-food SMEs logistics flow in the Loire region, and that 
takes into account sustainable development objectives with its three dimensions: economic, environmental and social.

The elements necessary for modeling the research question have now been identified and allowed a first proposal of the conceptual model. As future research lines, we are currently working on its validation in a real agri-food SMEs pooled network.

Acknowledgments. Authors would like to thank Region Rhône-Alpes for its financial support (Research Cluster GOSPI).

\section{References}

1. Rosen, M.-A., Kishawy, H.-A.: Sustainable Manufacturing and Design:Concepts, Practices and Needs. Sustainability (2012)

2. Camman, C., Livolsi, L.: La mutualisation logistique dans le canal de distribution: une strategie de contournement de la loi de modernisation de l'economie (2010)

3. Ülkü, M.-A.: Dare to care: Shipment consolidation reduces not only costs, but also environmental damage. International Journal of Production Economics (2011)

4. Wang, F., Lai, X., Shi, N.: A multi-objective optimization for green supply chain network design. Decision Support Systems (2011)

5. McCarter, M.G.: Northcraft Happy together? Insights and implications of viewing managed supply chains as a social dilemma. Journal of Operations Management (2007)

6. Piotrowicz, W., Cuthbertson, R.: A structured approach for assessing Suistainable best practices in supply chains. Environmental Issues in Logistics and Manufacturing (2012)

7. Conservatoire National des Arts et Métiers (CNAM).: Enquête Nationale: La logistique dans les PME-PMI de l'agroalimentaire, synthese des resultats. Chaire de Logistique, Transport, Tourisme (2007)

8. Pôle Agroalimentaire Loire, Organisation logistique du secteur agroalimentaire dans la Loire. Saint-Etienne (2011)

9. Moutaoukil, A., Derrouiche, R., Neubert, G.: Pooling Supply Chain: literature review of collaborative strategies. In: Camarinha-Matos, L.M., Xu, L., Afsarmanesh, H. (eds.) PROVE 2012. IFIP AICT, vol. 380, pp. 513-525. Springer, Heidelberg (2012)

10. Chen, H.: Mathematical model and solution approach for collaborative logistics in less than truckload (LTL) transportation. In: International Conference on Computers \& Industrial Engineering (2009)

11. Xuefeng, W.: An Integrated Multi-depot Location- inventory-routing Problem for Logistics Distribution System Planning of a Chain Enterprise. In: International Conference on Logistics Systems and Intelligent Management (2010)

12. Leitner, R., Meizer, F., Prochazka, M., Sihn, W.: Structural concepts for horizontal cooperation to increase efficiency in logistics. CIRP Journal of Manufacturing Science and Technology 4(3), 332-337 (2011)

13. Cruijssen, F.: Horizontal cooperation in transport and logistics. PhD thesis. Tilburg, Nederland (2006)

14. Ballot, E., Fontane, F.: Reducing transportation $\mathrm{CO} 2$ emissions through pooling of supply networks: perspectives from a case study in French retail chains. Production Planning \& Control: The Management of Operations 21(6), 640-650 (2010)

15. Howard, C., Marklund, J.: Evaluation of stock allocation policies in a divergent inventory system with shipment consolidation. European Journal of Operational Research (2011) 
16. Martel, M.: La collaboration dans le transport en Chargements Complets. Université Laval (2004)

17. Pan, S., Ballot, E., Fontane, F.: The reduction of greenhouse gas emissions from freight transport by merging supply chains. International Journal of Production Economics (2010)

18. Derrouiche, R., Neubert, G., Bouras, A., Savino, M.: B2B Relationship Management: A Framework to Explore Impact of Collaboration. International Journal of Production Planning \& Control (IJPPC) 21(6), 528-546 (2010)

19. Hickman, J., Hassel, D., Joumard, R., Samaras, Z., Sorenson, S.: Methodology for calculating transport emissions and energy consumption (Report for the Projet MEET). Transport Research Laboratory. Edinburgh (1999)

20. ADEME, Calcul des facteurs d'émissions et sources bibliographiques utilisées, Méthode bilan carbone. Agence de l'Environnement Mission Interministérielle et de la Maîtrise de l'Energie (2005)

21. CGDD, rapport du Commissariat général au développement durable, Transports et environnement: comparaisons européennes (2009) 